\title{
BLUETOOTH LOW ENERGY (BLE) FOR TRACKING AND DATA ANALYTICS TOWARDS MICE HYBRID VISITORS IN THE NEW NORMAL COVID-19 ERA
}

\author{
Maulahikmah Galinium \\ Swiss German University, Tangerang, Indonesia \\ maulahikmah.galinium@sgu.ac.id \\ Gregorius Ferdinand \\ Swiss German University, Tangerang, Indonesia \\ Daniel Amazia Dyondra \\ Swiss German University, Tangerang, Indonesia
}

Raka Zuhdi

Swiss German University, Tangerang, Indonesia

James Purnama

Swiss German University, Tangerang, Indonesia

I Eng Kho

Swiss German University, Tangerang, Indonesia

\begin{abstract}
MICE (Meeting, Incentive, Conference, Exhibition) has shown a significant promise in its industry growth by virtue of its usage in some Indonesia's big events, such as the 2018 G20 Summit held in Bali. MICE is important for seeing the visitors at a different angle, such as having an insight on the most visited booth of the event, how long the visitors spend time in one booth, and so on. The need of an application on this research for tracking visitors will be high especially during this Covid-19 pandemic. Therefore, to support the Indonesia economy recovery for years to come, especially on the MICE, a visitor tracking application is developed and tested. The purpose of this research is to develop algorithm for measuring the distance between visitors and the visitor density of a certain area in real time. This algorithm is implemented in the MICE event's visitor mobile tracking application which uses Internet of Things (loT) and Big Data Analytics as their foundation to embrace the new normal. The six BLE Beacons were tested by a testing app developed using a Javascript framework called React Native. The app is used to capture the packet broadcasted by the Beacons. The app uses a third-party library developed by Kontakt.io. In conclusion, among 6 beacons have been tested, Digoo Bytereal iBeacon BLE 4.0 and DS Beacon $\mathrm{V} 1.0$ are the most versatile and will be used in the next experiments.
\end{abstract}

Keywords: Hybrid MICE industry; Bluetooth Beacon; visitor tracking; big data analytics.

DOI: https://doi.org/10.24818/beman/2021.S.I.2-17 


\section{INTRODUCTION}

Indonesia is highly considered by the MICE tourism market as an attractive destination, for example in 2021, Indonesia will host the U-21 world cup and also one of the MotoGP series for the first time. It proofs the world community trust to carry out MICE activities in Indonesia (Ministry of Trade, Republic of Indonesia, 2011). The MICE industry is an activity that needs to be developed in terms of government regulations, event organizers and locations, as well as academic concepts so the MICE industry can run well (Buathong \& Lai, 2017). With the Covid-19 pandemic, ICT technology has also become indispensable for the sustainability of MICE activities in Indonesia (Disimulation, 2020). One of the Internet of Things (IOT)-based ICT research related to MICE is the study of one of the sensors, Smart Beacon, which is implemented into MICE activities using big data technology. Research conducted by Kim et.al. (2016) also monitors the movement and interaction of visitors during the event. However, this research has not solved the problem of social distancing in real time. Therefore, the main research problem is measuring the distance and density level of a certain location in real time. Currently, the use of Beacon sensors with Bluetooth Low Energy (BLE) signals can be measured using the Received Signal Strength Indication (RSSI) method. However, this RSSI method needs to be developed to support measurements quickly and in real time.

This research has a specific goal to develop an algorithm for measuring distance, density, and coordinates/location of visitors using BLE signals in real time. This is to support the implementation of tracking visitor movements and density levels in a venue so the social distancing can be recognized in real time. In the following year, it is necessary to prepare big data infrastructure to support the growing amount of data (scalable) and continue data analysis process of data obtained including Beacon sensor data, event management system data, and data from the event's social media using data mining techniques. The results of the data analysis will be visualized so it can be useful for the event organizers in making decisions. The urgency of this research during the Covid-19 pandemic is the movement of visitors is very important in preparing new normal arrangement in the MICE industry in the future. The event organizers can also find out number of visitors in real time so that it can be adjusted to the maximum capacity of the venue in order to comply with local government regulations.

\section{RELATED WORKS}

Although not much has been done, hybrid MICE events have been studied by Hamm et.al. (2018). In this study, Hamm defines hybrid MICE as combination of activities carried out with physical presence (face to face) and online using certain technologies to improve the visitor experience in attending the MICE event. The focus of this research is determining coordinate points, the distance 
between coordinates obtained in real time to support visitor tracking. Our previous research, tracking visitors using a QR-Code, was quite disturbing for visitors because visitors need to scan the QR-Code every time they are in a certain location (Wilbert, et.al., 2017). To improve the research, we then proceed with studying loT technology by using Beacons for tracking visitors with BLE technology which is implemented at the Museum (Widjaja, et.al., 2019).

Several methods have been carried out by other researchers in measuring distance, such as using the Received Signal Strength Indication (RSSI) method. Zhuan, et.al. (2016) used a Polynomial Regression Model (PRM), Finger Printing (FP) and Extended Kalman Filtering (EKF) to determine location in a smartphone-based closed room using a BLE Beacon. Furthermore, Huh and Seo (2017) used a rangeaverage algorithm using RSSI to determine the location in a closed room. RSSI results are still less accurate because they have a fairly high error rate, therefore Li et.al. (2018) used the RSSI real-time correction method using Bluetooth that is connected to a cloud server in a closed room. Because this Hybrid MICE activity can be carried out in a closed or open room, in this first year, the RSSI method for BLE will be used in combination with several other methods, namely with the addition of Global Positioning System (GPS) technology and also Near Field Communication (NFC). GPS technology combined with BLE Beacons will be very suitable for MICE activities in open spaces, while NFC combined with BLE Beacons can be used both in open and closed spaces requiring a closer distance. Therefore, the state of the art of this research is to combine several algorithms that can be used in several existing technologies (BLE Beacon, WIFI router, GPS, and NFC) to get more accurate coordinates and distance points so they can be implemented for social distancing purposes in real time. This combination has also been used by Cheng, et.al. (2016) to create a guide system for a location, both open and closed. As a continuation of social distancing, the density level in a room will also be measured using the Wasserstein interpolation method (Danis \& Cemgil, 2017) by calculating the distance between visitors as a whole.

Our previous research on big data infrastructure, one of which is the use of Hypervisor for education industry (Syahlie, et.al., 2014) and the use of Hadoop for performance optimization on servers (Christian, et.al, 2017). Several Natural Language Processing (NLP) methods are used to process free text from visitors on social media comments and from feedback on MICE activities. The processed free text is focused on Bahasa Indonesia. The NLP developed will go towards sentiment analysis to see how this MICE activity is discussed on various existing social media so the MICE activity organizers can evaluate it better in the coming years. Wijaya, et.al. (2013) used several algorithms, namely Support Vector Machine (SVM), Naïve Bayes and Decision tree for sentiment analysis. The same method is also used to process the data in this study. Data from social media will be retrieved using tools such as RapidMiner, which will then be used as a training set. Preprocessing is carried out to eliminate less 
important words such as in, to, and so on, which are then analyzed with several machine learning algorithms, such as Support Vector. Machine (SVM), Naïve Bayes and Decision tree for sentiment analysis.

\section{METHOD}

The methodology that will be used in this research is method for determining coordinates, distance and density in a MICE event. This method is implemented in the development of a visitor tracking mobile application. Specific research on event management has started since 2018, starting with event management using a QR-Code and tour guide application development using Beacon sensor to improve the visitor experience in an event. This research will focus on determining coordinates, distance and density of MICE visitors in the context of social distancing in real time to support new normal activities. It is done based on Internet of Things (IOT) technology. By using BLE Beacon technology, the mobile application will be convenient to use by the visitors. This concept is called unobtrusive visitor tracking. Unlike previous research using a QR-Code, where visitors are required to scan the QR-Code at every location/booth they visit. The several stages conducted in this research as follow:

1. Trial with several types of BLE Beacon sensors using several methods to determine coordinates, distance and density of a room, both closed and open, namely: Received Signal Strength Indication (RSSI), Polynomial Regression Model (PRM), Finger Printing (FP) and Extended Kalman Filtering (EKF). The BLE Beacon sensors that will be used are the RadBeacon chip, HM-10 Bluetooth Beacon, Shenzhen Minew Bluetooth Beacon, Aruba Beacon and Estimote Beacon.

2. Development of concept proof from the results of the BLE Beacon trial into the creation of a mobile application starting with the analysis and design system of the application to the integration of the method of determining coordinates, distances and density into the application.

3. Test the mobile app with partners and some users to get feedback.

The research started with testing and experimenting using RFID reader, RFID labels, and RFID cards to see how well the RFID reader detects nearby RFID labels and RFID cards, as a way of measuring distance, density, and coordinates/location of visitors. We use one CT-i808 RFID reader, ten UHF Alien H3 RFID labels, and ten Alien H3 UHF ISO cards in this research. However, this method has been paused as our research and analysis showed that RFID signals are easily interrupted by any object or person blocking the RFID label/card from the RFID reader. This situation caused any RFID labels or RFID cards be undetectable by the RFID reader itself. Therefore, we have decided to focus on the use of Beacon sensors with Bluetooth Low Energy (BLE), as the signals generated from the Beacon 
Galinium, M., Ferdinand, G., Dyondra, D.A., Zuhdi, R., Purnama, J., Kho, I.E. BLUETOOTH LOW ENERGY (BLE) FOR TRACKING AND DATA ANALYTICS TOWARDS MICE HYBRID VISITORS IN THE NEW NORMAL COVID-19 ERA

sensors itself are not easily interrupted. To determine which Beacon is more suitable for the research, six different types of Beacons were tested and compared. The six types of Beacons were:

1. BLE Beacon with Motion sensor accelerometer sensor push button loT iBeacon. (KBeacon)

2. IBeacons Type bluetooth 4.0 Module NRF51822 Chipset IBeacon. (Digoo Blue)

3. FEASYCOM Mini Bluetooth 5.0 Proximity Low Energy Beacon with Eddystone, iBeacon and AltBeacon,Android \& iOS Programmable. (Feasycom)

4. Radius Networks RadBeacon Dot - Proximity Beacon with Eddystone, iBeacon and AltBeacon Technology. (RadBeacon)

5. Digoo Product Bytereal iBeacon BLE 4.0 Near Field Orientation Modul 9y. (Digoo Cube)

6. DS Beacon V1.0. (DS Beacon)

The six BLE Beacons were tested by a testing app developed using a Javascript framework called React Native. The app is used to capture the packet broadcasted by the Beacons. The app uses a third-party library developed by Kontakt.io, an industry that specializes in indoor location services and BLE Beacons (MIT License, 2020). The library was used to parse the Beacon packets and wrap them into a JSON object that contains information about the Beacon as shown in Fig. 1. The parsed value of the Beacon packet is an array of JSON objects. The JSON object attributes are:

1. Accuracy: An estimated distance by the library between the Beacon and the mobile phone.

2. Address: The Mac Address of the BLE Beacon. It is a unique identifier to be used as a network address.

3. BatteryPower: An estimate of the BLE Beacon battery power.

4. UUID (Universally Unique Identifier): 32 hexadecimal digits, split into 5 groups and separated by hyphens used to distinguish the BLE Beacon.

5. Major and Minor values: Assigned numbers to identify the BLE Beacon with greater accuracy than just UUID.

6. RSSI (Received Signal Strength Indication): The measurement of the power received from a signal. It is used to indicate signal strength coming from the Beacon. The closer it is to positive value, the closer the signal source is.

7. Name: The Beacon type.

8. Proximity: The approximate distance of the source. 
Galinium, M., Ferdinand, G., Dyondra, D.A., Zuhdi, R., Purnama, J., Kho, I.E. BLUETOOTH LOW ENERGY (BLE) FOR TRACKING AND DATA ANALYTICS TOWARDS MICE HYBRID VISITORS IN THE NEW NORMAL COVID-19 ERA

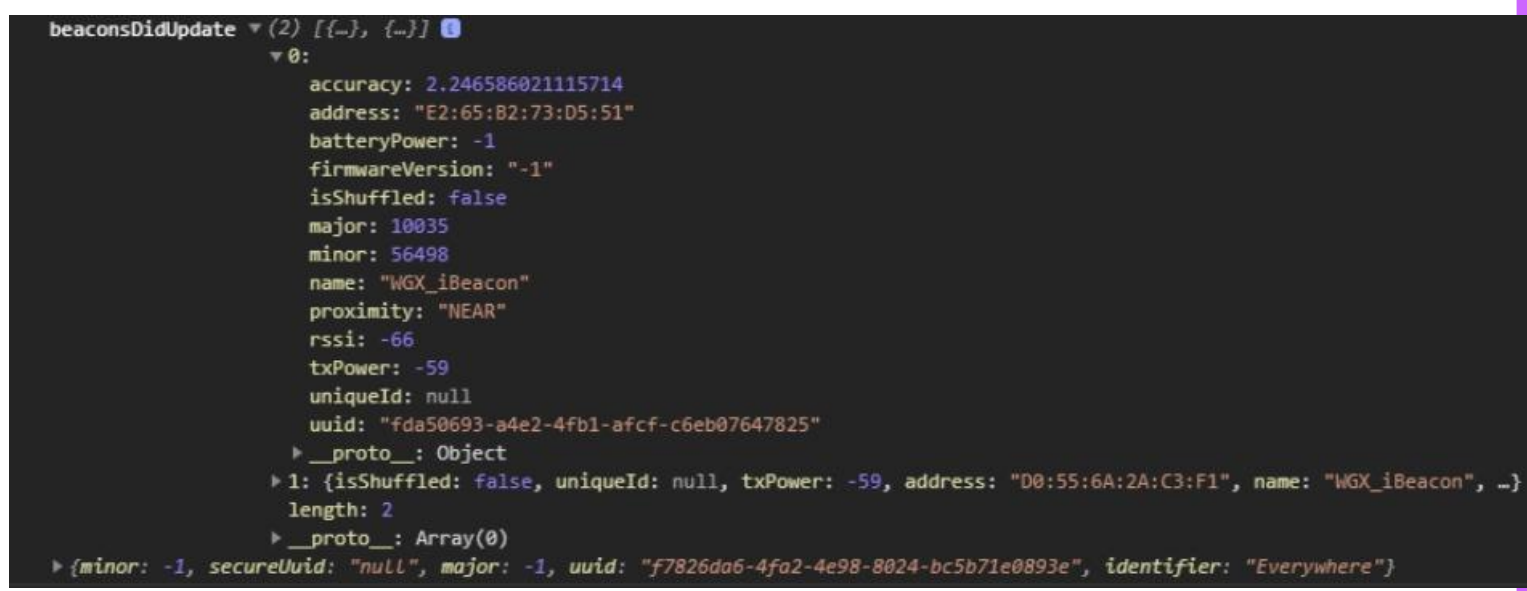

FIGURE 1. KONTAKT.IO LIBRARY PACKET

Source: MIT LICENSE, 2020

The smartphone used during testing procedure was a Xiaomi Redmi Note 7 android smartphone with an Android version 10 QKQ1.190910.002, Bluetooth V5, 4GB RAM, and Octa-core Max 2.20GHz CPU, as shown in Fig. 2. The main information required to calculate distance between the mobile phone and the Beacon are the RSSI and the Mac Address of the BLE Beacon. Furthermore, the library also includes a function that shows estimated distance between the mobile phone and the BLE Beacon. Below are the parameters that can be set in the app:

1. TxPower : The measured power of the Beacon or the RSSI value of the Beacon when it is $1 \mathrm{~m}$ range to the receiving devices.

2. Environmental Factor: A path loss exponent constant that depends on the environmental factor. It ranges from 2-4. This parameter is used to set the sensitivity of the Beacon. The higher the value, the more sensitive it becomes. Therefore, the denser the area, the better it is to increase the value of the environmental factor constant.

3. Test count: The amount of tests will be conducted ( 1 test $=30$ second).

4. Beacon mac address: The mac address of the Beacon being tested. 


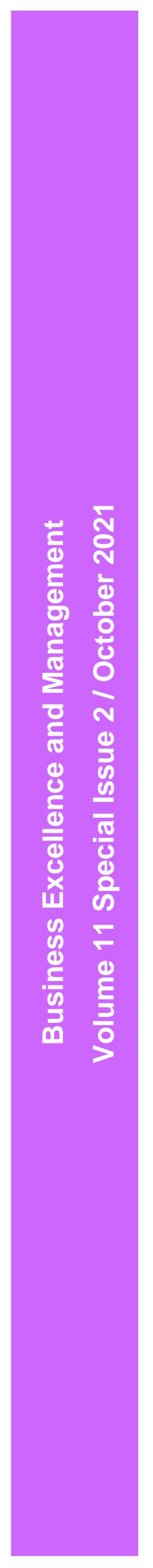

Galinium, M., Ferdinand, G., Dyondra, D.A., Zuhdi, R., Purnama, J., Kho, I.E. BLUETOOTH LOW ENERGY (BLE) FOR TRACKING AND DATA ANALYTICS TOWARDS MICE HYBRID VISITORS IN THE NEW NORMAL COVID-19 ERA

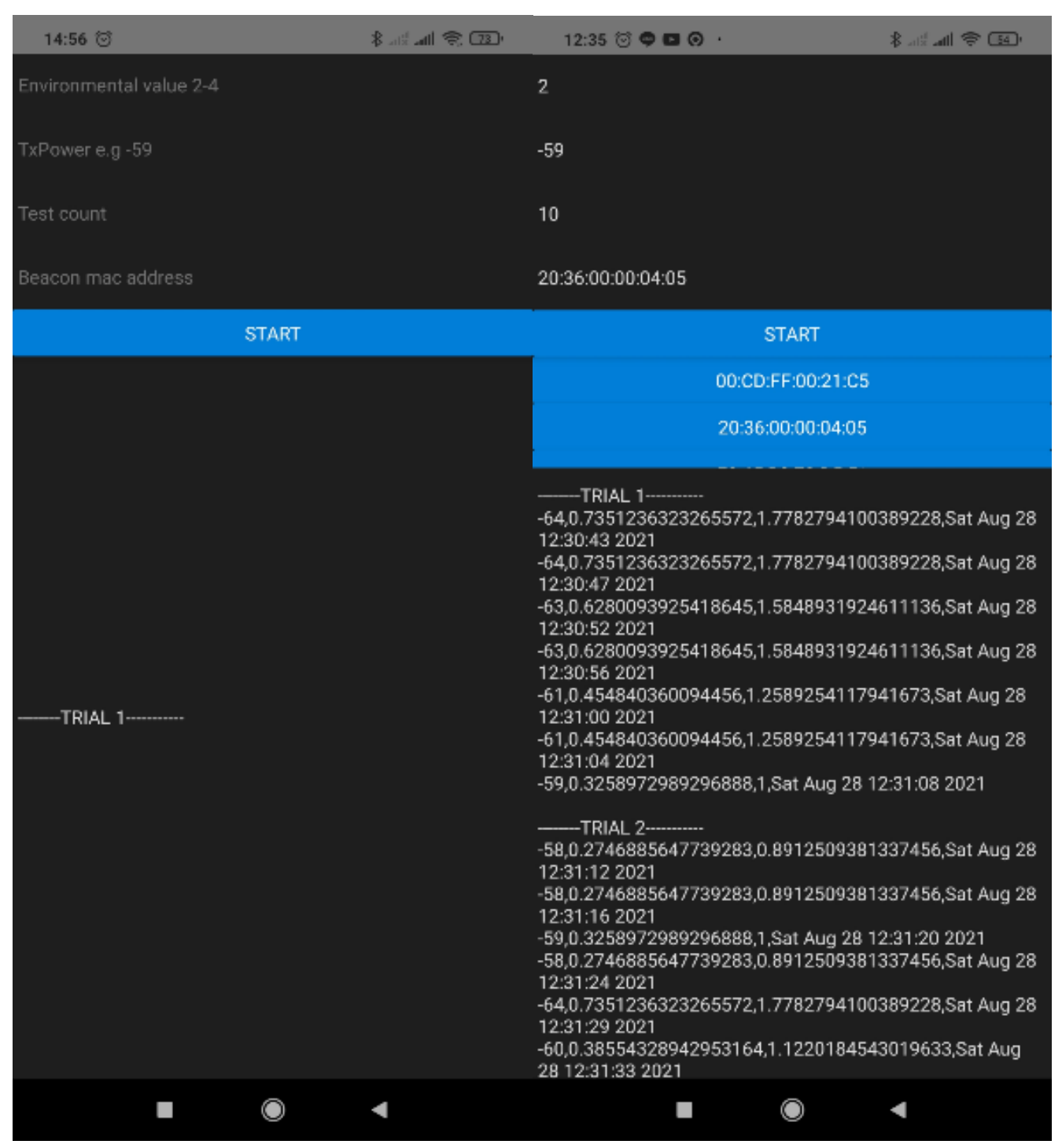

FIGURE 2. TESTING APPLICATION

Source: The Authors

After a test, an output of CSV formatted data will be produced as shown in Fig.3. The test can be repeated automatically depending on the test count parameter. Respectively, the columns of the CSV data are stated below:

1. RSSI.

2. Estimated distance using the Kontakt.io library.

3. Estimated distance using the IOT and Electronics formula.

4. Current date and time to calculate time interval after every test. 
Galinium, M., Ferdinand, G., Dyondra, D.A., Zuhdi, R., Purnama, J., Kho, I.E.

\begin{tabular}{|c|c|c|c|}
\hline A & B & c & D \\
\hline RSSI & Kontakt.io & IOT and Electronics Formula & Date \\
\hline \multicolumn{4}{|c|}{ 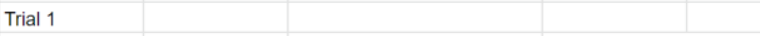 } \\
\hline-54 & 0.412494 & 0.562341 & Sat Jun 5 15:54:53 2021 \\
\hline-51 & 0.232907 & 0.398107 & Sat Jun 5 15:54:56 2021 \\
\hline-53 & 0.342167 & 0.501187 & Sat Jun 5 15:54:59 2021 \\
\hline-51 & 0.232907 & 0.398107 & Sat Jun 5 15:55:04 2021 \\
\hline-51 & 0.232907 & 0.398107 & Sat Jun 5 15:55:07 2021 \\
\hline-53 & 0.342167 & 0.501187 & Sat Jun 5 15:55:10 2021 \\
\hline-58 & 0.842868 & 0.891251 & Sat Jun 5 15:55:13 2021 \\
\hline-59 & 1.01076 & 1 & Sat Jun 5 15:55:16 2021 \\
\hline-58 & 0.842868 & 0.891251 & Sat Jun 5 15:55:19 2021 \\
\hline \multicolumn{4}{|l|}{ Trial 2} \\
\hline-57 & 0.708318 & 0.794328 & Sat Jun 5 15:55:41 2021 \\
\hline-56 & 0.593417 & 0.707946 & Sat Jun 5 15:55:45 2021 \\
\hline-55 & 0.495572 & 0.630957 & Sat Jun 5 15:55:48 2021 \\
\hline-56 & 0.593417 & 0.707946 & Sat Jun 5 15:55:51 2021 \\
\hline-56 & 0.593417 & 0.707946 & Sat Jun 5 15:55:54 2021 \\
\hline-58 & 0.842868 & 0.891251 & Sat Jun 5 15:55:57 2021 \\
\hline-56 & 0.593417 & 0.707946 & Sat Jun 5 15:56:01 2021 \\
\hline-57 & 0.708318 & 0.794328 & Sat Jun 5 15:56:04 2021 \\
\hline-57 & 0.708318 & 0.794328 & Sat Jun 5 15:56:07 2021 \\
\hline \multicolumn{4}{|l|}{ Trial 3} \\
\hline-54 & 0.412494 & 0.562341 & Sat Jun 5 15:56:28 2021 \\
\hline-56 & 0.593417 & 0.707946 & Sat Jun 5 15:56:32 2021 \\
\hline-52 & 0.282822 & 0.446684 & Sat Jun 5 15:56:35 2021 \\
\hline-52 & 0.282822 & 0.446684 & Sat Jun 5 15:56:38 2021 \\
\hline-58 & 0.842868 & 0.891251 & Sat Jun 5 15:56:41 2021 \\
\hline-56 & 0.593417 & 0.707946 & Sat Jun 5 15:56:44 2021 \\
\hline-58 & 0.842868 & 0.891251 & Sat Jun 5 15:56:47 2021 \\
\hline-56 & 0.593417 & 0.707946 & Sat Jun 5 15:56:50 2021 \\
\hline-54 & 0.412494 & 0.562341 & Sat Jun 5 15:56:54 2021 \\
\hline-57 & 0.708318 & 0.794328 & Sat Jun 5 15:56:57 2021 \\
\hline
\end{tabular}

FIGURE 3. CSV FORMATTED DATA

Source: The Authors

For calculating the distance, the app uses a function from the Kontakt.io library and a formula from IOT and Electronics as we are trying to find the most suitable formula/function to be used (iotbymukund, 2016).

$$
\text { Distance }=10^{\left(\frac{\text { Measured Power }- \text { RSSI }}{10 \cdot \text { Environmental Factor }}\right)}
$$

Equation 1 shows the following parameters:

1. Measured Power: A read only calibrated constant that indicates the expected RSSI when it is $1 \mathrm{~m}$ in range to receiving devices.

2. RSSI: Received Signal Strength Indicator, which shows signal strength generated by each Beacon. The signal strength depends on the distance and the broadcasting power.

3. Environmental Factor: A path loss exponent constant that depends on the environmental factor. It ranges from 2-4. This parameter is used to set sensitivity of the Beacon. The higher the value, the 
more sensitive it becomes. Therefore, the denser the area, the better it is to increase the value of the environmental factor constant.

\section{RESULT AND ANALYSIS}

Each Beacon type was tested with the React JavaScript testing app containing a library/formula from Kontakt.io using a Xiaomi Redmi Note 7 android smartphone in indoor environment. The testing procedure started by marking the floor by multiples of $100 \mathrm{~cm}$ to $500 \mathrm{~cm}$, and each Beacon type is tested 10 times at each distance for 30 seconds each. Every data packet received by each Beacon contains data of RSSI, calculation result from Kontakt.io library calculation result from IOT and Electronics formula, and time the data packet is received by the application (MIT License, 2020). The data received by the application is then recorded into a spreadsheet and is later compared by variance, standard deviation, average RSSI, average distance result calculated using Kontakt.io library and IOT and Electronics formula, and average number of packets received from each Beacon.

The table 1 shows average value of RSSI received from 10 trials of testing, in which every trial takes up 30 seconds. The data is processed to calculate accuracy of the RSSI value. The expected RSSI value received is -59 when the distance between the Beacon and the phone is $100 \mathrm{~cm}$.

\section{TABLE 1. AVERAGE VALUE OF RSSI}

\begin{tabular}{|l|l|l|l|l|l|l|}
\hline \multicolumn{7}{c}{ Average Value of RSSI of 10 Trials } \\
\hline distance in cm & RadBeacon Dot & Beacon NRF51822 & Byetereal iBeacon & FSC-BP103B & CC2640 R2F & iBeacon NRF52832 DS-Beacon \\
\hline 100 & -61.45945946 & -58.33333333 & -58.31914894 & -84.26027397 & -69.53521127 & -58.30555556 \\
\hline 200 & -69.58108108 & -65.15909091 & -64.03191489 & -82.015625 & -73.3015873 & -65.97222222 \\
\hline 300 & -73.17808219 & -70.87628866 & -68.32978723 & -87.73584906 & -74.65671642 & -69.85507246 \\
\hline 400 & -76.01369863 & -73.12903226 & -69.18085106 & -87.12765957 & -75 & -71.91304348 \\
\hline 500 & -82.20547945 & -73.72631579 & -77.98947368 & -86.05555556 & -75.38571429 & -73 \\
\hline
\end{tabular}

Source: The Authors

The table 2 shows percent error of the RSSI value with a distance of $100 \mathrm{~cm}$ from the mobile phone. Sorted BLE Beacon names in terms of percentage error of RSSI accuracy from the lowest to the highest respectively: iBeacon NRF51822, Bytereal iBeacon, iBeacon NRF 52832 DS-Beacon, RadBeacon Dot, CC2640 R2F, FSC-BP103B.

TABLE 2. PERCENTAGE ERROR OF RSSI ACCURACY

\begin{tabular}{|c|c|c|c|c|c|}
\hline & \multicolumn{5}{c|}{ Percantage Error of RSI Accuracy (unit in percenti) } \\
\hline RadBeacon Dot & Beacon NRF51822 & Bytereal Beacon & FSC-BP103B & K Beacon & iBeacon NRF52832 DS-Beacon \\
\hline 4.168575356 & 1.129943508 & 1.153984847 & 42.81402368 & 17.85629029 & 1.177024475 \\
\hline
\end{tabular}

Source: The Authors 
Galinium, M., Ferdinand, G., Dyondra, D.A., Zuhdi, R., Purnama, J., Kho, I.E.

BLUETOOTH LOW ENERGY (BLE) FOR TRACKING AND DATA ANALYTICS TOWARDS MICE HYBRID VISITORS

IN THE NEW NORMAL COVID-19 ERA

The table 3 shows the ranking based on signal stability. Sorted BLE Beacon names from the highest RSSI stability to the lowest RSSI stability: iBeacon NRF52832 DS-Beacon, Bytereal iBeacon, RadBeacon Dot, FSC-BP103B, CC2640R2F, iBeacon NRF51822.

TABLE 3. RANKING IN TERMS OF SIGNAL STABILITY

\begin{tabular}{|c|c|c|c|c|c|}
\hline $\begin{array}{l}\text { Ranking in terns of signal } \\
\text { stability }\end{array}$ & $100 \mathrm{~cm}$ & $200 \mathrm{~cm}$ & $300 \mathrm{~cm}$ & $400 \mathrm{~cm}$ & $500 \mathrm{~cm}$ \\
\hline 1 & Beacon NRF52632 OS-Beacon & Bytereal ieacon & iBeacon NRF52632 DS-Beacon & iBeacon NRF52632 OS-Beacon & Byetereal ieeacon \\
\hline 2 & Radeacon Dot & Radeeacon Dot & Byetereal iBeacon & FSC-BP103B & iBeacon NRF52832 OS-Beacon \\
\hline 3 & Byetereal iBeacon & Beacon NRF52632 DS-Beacon & FSC-BP103B & Radieacon Dot & FSC-BP103B \\
\hline 4 & FSC-BP103B & FSC-BP103B & RadBeacon Dot & Byetereal iBeacoxi & $\mathrm{CC} 2640 \mathrm{R} 2 \mathrm{~F}$ \\
\hline 5 & Beacon NRF51622 & $\mathrm{CC} 2640 \mathrm{R} 2 \mathrm{~F}$ & $\mathrm{CC} 2640 \mathrm{R} 2 \mathrm{~F}$ & $\mathrm{CC} 2640 \mathrm{R} 2 \mathrm{~F}$ & Radideacon Dol \\
\hline 6 & $\mathrm{CC} 2640 \mathrm{R} 2 \mathrm{~F}$ & Bcacon NRF51822 & Becacon NRF51822 & Beacon NRF51822 & iBcacon NRF51822 \\
\hline
\end{tabular}

Source: The Authors

The table 4 and 5 shows average distance calculated by using distance calculation formula by IOT and Electronics (Table 4) and by Kontakt.io (Table 5). The environmental factor constant of the IOT and Electronics formula was set to 2 because the testing environment was not dense. In other words, the testing environment had minimal objects and people in the vicinity. The delta shows the difference between actual distance of the Beacon and distance calculated by using the formula. The percent error method was implemented to measure percentage error of the actual distance and the estimated distance.

\section{TABLE 4. AVERAGE DISTANCE CALCULATED USING IOT AND ELECTRONICS FORMULA}

\begin{tabular}{|l|c|c|c|c|c|c|}
\hline \multicolumn{5}{|c|}{ Average Distance Calculated Using IOT and Electronics Formula (Environmental Factor = 2) } \\
\hline distance in cm & RadBeacon Dot & iBeacon NRF51822 & Bytereal iBeacon & FSC-BP103B & CC2640 R2F & iBeacon NRF52832 DS-Beacon \\
\hline 100 & 122.552873 & 101.8187333 & 97.84775098 & 1992.154213 & 79.43282347 & 92.97281417 \\
\hline delta $100 \mathrm{~cm}$ & 22.552873 & 1.8187333 & -2.15224902 & 1892.154213 & -20.56717653 & -7.02718583 \\
\hline 200 & 226.9183905 & 288.6922966 & 181.1779 & 1543.660541 & 622.5946236 & 234.7058147 \\
\hline delta $200 \mathrm{~cm}$ & 26.9183905 & 88.6922966 & -18.8221 & 1343.660541 & 422.5946236 & 34.7058147 \\
\hline 300 & 586.8698288 & 492.4387268 & 310.5654191 & 2879.494636 & 696.8208039 & 365.7629352 \\
\hline delta $300 \mathrm{~cm}$ & 286.8698288 & 192.4387268 & 10.5654191 & 2579.494636 & 396.8208039 & 65.7629352 \\
\hline 400 & 781.0330466 & 629.1295355 & 355.5323116 & 2724.816204 & 736.4045 & 456.4355794 \\
\hline delta $400 \mathrm{~cm}$ & 381.0330466 & 229.1295355 & -44.4676884 & 2324.816204 & 336.4045 & 56.4355794 \\
\hline 500 & 1705.089858 & 751.44646 & 959.3531933 & 2500.039405 & 767.3271489 & 527.474323 \\
\hline delta $500 \mathrm{~cm}$ & 1205.089858 & 251.44646 & 459.3531933 & 2000.039405 & 267.3271489 & 27.474323 \\
\hline average delta & 384.4927994 & 152.7051504 & 80.895315 & 2028.033 & 280.51598 & 35.47029329 \\
\hline
\end{tabular}

Source: The Authors 
Galinium, M., Ferdinand, G., Dyondra, D.A., Zuhdi, R., Purnama, J., Kho, I.E. BLUETOOTH LOW ENERGY (BLE) FOR TRACKING AND DATA ANALYTICS TOWARDS MICE HYBRID VISITORS IN THE NEW NORMAL COVID-19 ERA

\section{TABLE 5. AVERAGE DISTANCE CALCULATED USING KONTAKT.IO LIBRARY}

\begin{tabular}{|l|c|c|c|c|c|c|}
\hline \multicolumn{7}{c|}{ Average Distance Calculated Using Kontakt.io Library } \\
\hline distance in cm & RadBeacon Dot & iBeacon NRF51822 & Bytereal iBeacon & FSC-BP103B & CC2640 R2F & iBeacon NRF52832 DS-Beacon \\
\hline 100 & 12.76626351 & 96.21955161 & 92.36616304 & 242.3376864 & 394.2316252 & 29.36415752 \\
\hline delta $100 \mathrm{~cm}$ & -87.23373649 & -3.78044839 & -7.63383696 & 142.3376864 & 294.2316252 & -70.63584248 \\
\hline 200 & 42.32993514 & 275.7587886 & 182.6009288 & 198.4808395 & 555.8265209 & 100.7846868 \\
\hline delta $200 \mathrm{~cm}$ & -157.6700649 & 75.7587886 & -17.3990712 & -1.5191605 & 355.8265209 & -99.2153132 \\
\hline 300 & 74.99561644 & 446.0249361 & 303.3475419 & 320.5037451 & 618.6254087 & 155.3798435 \\
\hline delta $300 \mathrm{~cm}$ & -225.0043836 & 146.0249361 & 3.3475419 & 20.5037451 & 318.6254087 & -144.6201565 \\
\hline 400 & 102.3353973 & 553.6436624 & 342.8800448 & 306.1774053 & 592.780177 & 189.5621281 \\
\hline delta $400 \mathrm{~cm}$ & -297.6646027 & 153.6436624 & -57.1199552 & -93.8225947 & 192.780177 & -210.4378719 \\
\hline 500 & 191.2878384 & 624.3655379 & 822.5352955 & 285.2401017 & 670.0332964 & 212.8234682 \\
\hline delta $500 \mathrm{~cm}$ & -308.7121616 & 124.3655379 & 322.5352955 & -214.7598983 & 170.0332964 & -287.1765318 \\
\hline average delta & -215.2569898 & 99.20249532 & 48.74599481 & -29.4520444 & 266.2994056 & -162.4171432 \\
\hline
\end{tabular}

Source: The Authors

Respectively Table 6 and 7 show the percentage error of distance calculated using IOT and Electronics Formula. The bottom row is the average percentage error. The lower the average percentage, the more accurate the result is. Sorted list of BLE Beacon in terms of distance accuracy when calculated using the IOT and Electronics Formula from the highest accuracy to the lowest accuracy: 1) iBeacon NRF52832 DS-Beacon, 2) Bytereal iBeacon, 3) iBeacon NRF51822, 4) RadBeacon Dot, 5) CC2640 R2F, 6) FSC-BP103B. Sorted list of BLE Beacon in terms of distance accuracy when calculated using the Kontakt.io from the highest accuracy to the lowest accuracy: 1) Bytereal iBeacon, 2) iBeacon NRF51822, 3) FSC-BP103B, 4) iBeacon NRF52832 DS-Beacon, 5) RadBeacon Dot, 6) CC2640 R2F.

TABLE 6. PERCENTAGE ERROR OF DISTANCE CALCULATED USING IOT AND ELECTRONICS FORMULA.

\begin{tabular}{|c|c|c|c|c|c|c|}
\hline \multirow[b]{2}{*}{ Distance } & \multicolumn{6}{|c|}{ Percentage error of distance calculated using IOT and Electronics Formula (unit in percent) } \\
\hline & RadBeacon Dot & iBeacon NRF51822 & Bytereal iBeacon & FSC-BP103B & CC2640 R2F & iBeacon NRF52832 DS-Beacon \\
\hline $100 \mathrm{~cm}$ & 22.552873 & 1.8187333 & 2.15224902 & 1892.154213 & 20.56717653 & 7.02718583 \\
\hline $200 \mathrm{~cm}$ & 13.45919525 & 44.3461483 & 9.41105 & 671.8302705 & 211.2973118 & 17.35290735 \\
\hline $300 \mathrm{~cm}$ & 95.62327627 & 64.14624227 & 3.521806367 & 859.8315453 & 132.2736013 & 21.9209784 \\
\hline $400 \mathrm{~cm}$ & 95.25826165 & 57.28238388 & 11.1169221 & 581.204051 & 84.101125 & 14.10889485 \\
\hline $500 \mathrm{~cm}$ & 241.0179716 & 50.289292 & 91.87063866 & 400.007881 & 53.46542978 & 5.4948646 \\
\hline Average & 93.58231555 & 43.57655995 & 23.61453323 & 881.0055922 & 100.3409289 & 13.18096621 \\
\hline
\end{tabular}

Source: The Authors 
Galinium, M., Ferdinand, G., Dyondra, D.A., Zuhdi, R., Purnama, J., Kho, I.E.

BLUETOOTH LOW ENERGY (BLE) FOR TRACKING AND DATA ANALYTICS TOWARDS MICE HYBRID VISITORS

IN THE NEW NORMAL COVID-19 ERA

TABLE 7. PERCENTAGE ERROR OF DISTANCE CALCULATED USING KONTAKT.IO LIBRARY

\begin{tabular}{|l|c|c|c|c|c|c|c|}
\hline & \multicolumn{5}{|c|}{ Percentage error of distance calculated using } & Kontakt.io (unit in percent) \\
\cline { 2 - 7 } & RadBeacon Dot & iBeacon NRF51822 & Bytereal iBeacon & FSC-BP103B & CC2640 R2F & iBeacon NRF52832 DS-Beacon \\
\hline $100 \mathrm{~cm}$ & 87.23373649 & 3.78044839 & 7.63383696 & 142.3376864 & 294.2316252 & 70.63584248 \\
\hline $\mathbf{2 0 0} \mathrm{cm}$ & 78.83503243 & 37.8793943 & 8.6995356 & 0.75958025 & 177.9132605 & 49.6076566 \\
\hline & & & & & & \\
\hline
\end{tabular}

Source: The Authors

Table 8 shows the average number of packets received in 30 seconds. In other words, it shows the average number of packets received by the mobile app in under 30 seconds. This data is used to measure the signal strength. The higher the number of packets sent, the stronger the signal is. Sorted list of BLE Beacon from the highest signal strength to the lowest signal strength: 1) iBeacon NRF51822, 2) Bytereal iBeacon, 3) iBeacon NRF52832 DS-Beacon, 4) RadBeacon Dot, 5) CC2640 R2F, 6) FSCBP103B.

TABLE 8. AVERAGE NUMBER OF PACKET RECEIVED IN 30 SECONDS

\begin{tabular}{|l|c|c|c|c|c|c|c|}
\hline \multicolumn{7}{|c|}{ Average \# of Packet Received in 30 Seconds } \\
\hline distance in cm & RadBeacon Dot & iBeacon NRF51822 & Bytereal iBeacon & FSC-BP103B & CC2640 R2F & iBeacon NRF52832 DS-Beacon \\
\hline 100 & 7.4 & 9.3 & 9.4 & 7.222222222 & 6.454545455 & 7.9 \\
\hline 200 & 7.4 & 10.4 & 9.4 & 6.1 & 6.3 & 7.9 \\
\hline 300 & 6.636363636 & 9.7 & 9.4 & 5.888888889 & 6.7 & 7.9 \\
\hline 400 & 7.333333333 & 9.3 & 9.2222222 & 5.222222222 & 6.272727273 & 7.9 \\
\hline 500 & 7.3 & 9.5 & 9.5 & 5.888888889 & 6.363636364 & 7.92 \\
\hline average & 7.213939394 & 9.64 & 9.38444444 & 6.064444444 & 6.418181818 & \\
\hline
\end{tabular}

Source: The Authors

The main objective of this BLE Beacon comparison is to find the most optimal Beacon for the research. There are several traits to be looked for to find the most optimal Beacon: accuracy, signal stability, and signal strength. From this comparison result, it can be seen that iBeacon NRF51822 and Bytereal iBeacon are the most versatile among all the BLE Beacons we've tested thus far based on their overall performance. Each Beacon's stability and accuracy is compared by variance, standard deviation, average RSSI, average distance result calculated from Kontakt.io and the formula from IOT and Electronics, and average number of packets received from each Beacon. The Beacon sensor that will be used for this research is the one with variance that has least difference between each distance. Based on results from Beacon systems that we've compared and calculated in the spreadsheet, we can 
conclude that Digoo Bytereal iBeacon BLE 4.0 and DS Beacon V1.0 are the most versatile among all the Beacon systems we've tested thus far.

As shown in the Fig. 4, the BLE Beacon would broadcast a packet which contains RSSI signals that would be received by the mobile application via Bluetooth. The mobile application would send the RSSI, the mac address received from the Beacon, as well as the user id to the backend server where the RSSI and mac address are sent to the MySQL database. If the database query is successful in finding the Beacon by the RSSI and mac address, the Beacon packets would be sorted to find the most positive RSSI value to identify user location with the highest occurrence Beacon. Once the Beacon with the highest occurrence is found, the MySQL database would update the user location. It will then be returned to the mobile app, showing the user his/her location.

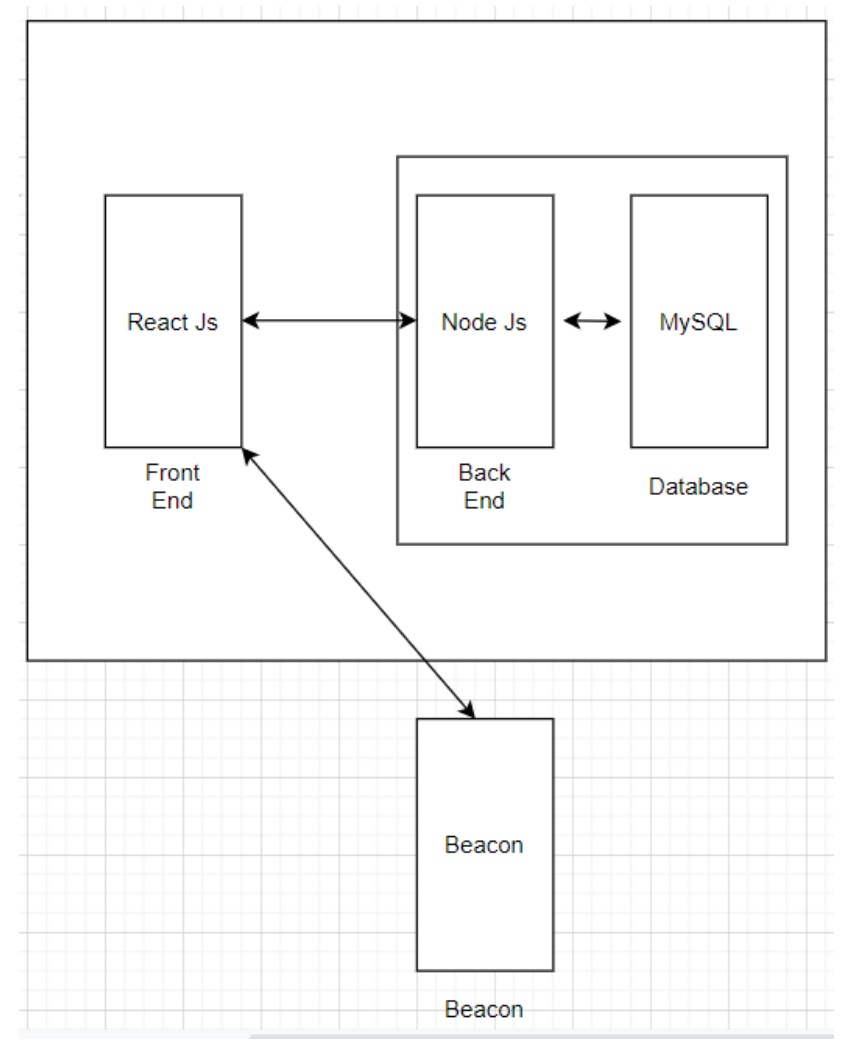

FIGURE 4. ARCHITECTURE DIAGRAM

Source: The Authors

Fig. 5 shows the Activity Diagram how users can use the application, which user types have access to certain features of the app, as well as how the app receives packets from the Beacons. As shown in the Activity Diagram, the user will open the app to either register an account or log in, depending whether the user already has an account or not. If the user does not have an account, the user will have to register his/her data using the "Register" feature which will then be stored into the 
Galinium, M., Ferdinand, G., Dyondra, D.A., Zuhdi, R., Purnama, J., Kho, I.E. BLUETOOTH LOW ENERGY (BLE) FOR TRACKING AND DATA ANALYTICS TOWARDS MICE HYBRID VISITORS IN THE NEW NORMAL COVID-19 ERA

database. The user can then log in to the app through the "Login" feature, which will then be verified by the app by looking up the user's email address and password in the database through endpoint in the backend server. Once the user has successfully logged in, the user will be redirected to the main menu, where the user is able to view details of the event, event schedule, and heat map. Some features of the application are only available to Event Admins, these features include "Edit Event Details", "Edit Event Schedule", and "Booth Statistics" (which is also accessible by Booth Owners). The application will start receiving packages from the BLE Beacons which will be automatically sent to the backend server every $x$ seconds. The data then will be processed and sent to the database. The mobile app will then fetch the data through an endpoint to the database every $x$ seconds to determine the user location which will appear on the app's Heat Map.

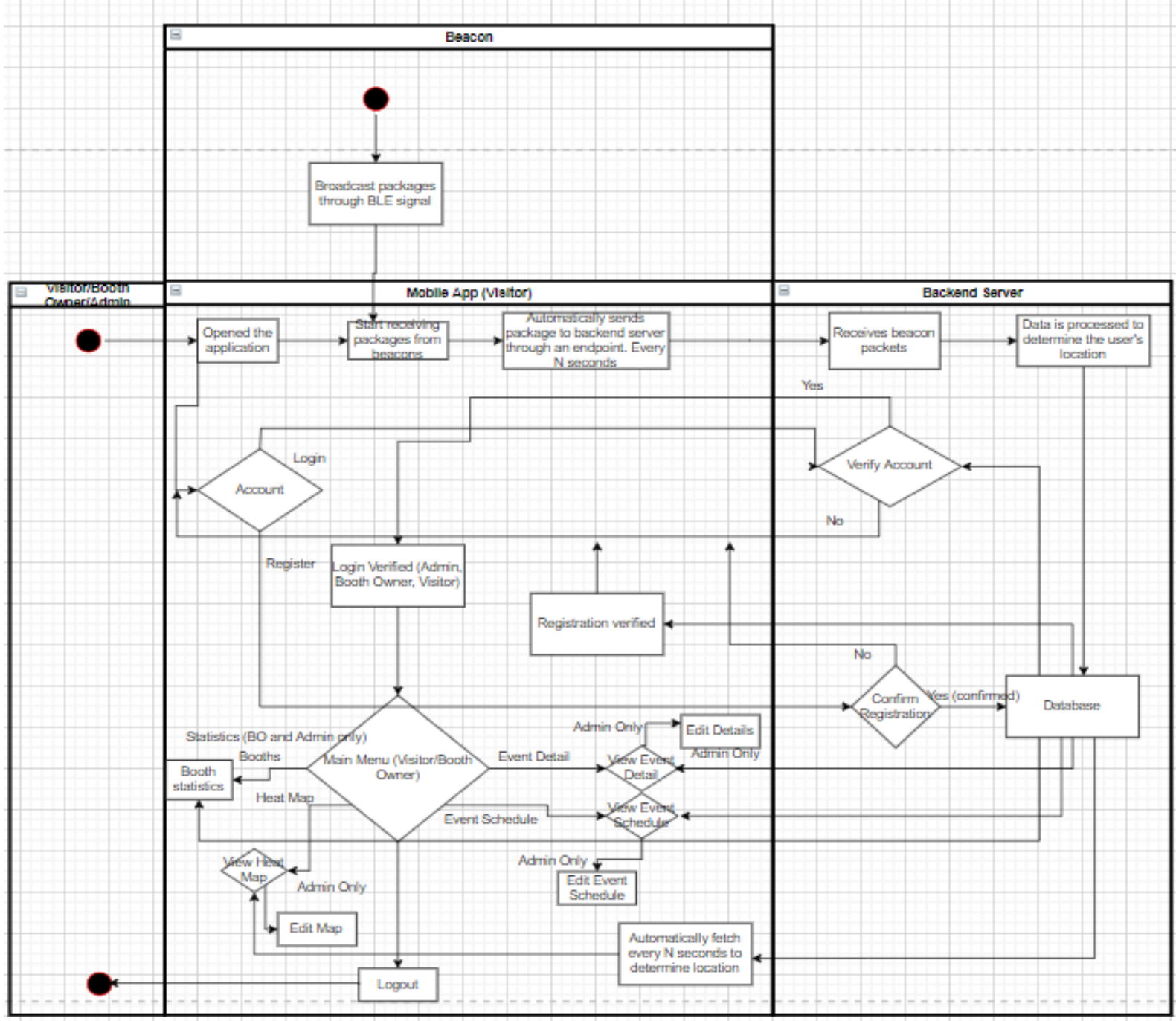

FIGURE 5. ACTIVITY DIAGRAM

Source: The Authors 


\section{CONCLUSIONS}

The purpose of this research is to enforce social distancing between visitors in local physical MICE events. Based on conducted experiments and analysis, it is shown that Bluetooth low energy Beacon systems are capable in transmitting signals via Bluetooth without any interference. Therefore, it is decided to use Bluetooth low energy Beacon systems in our mobile app. It will enable event administrators to track and figure out location of every person attending a physical MICE event, to notify app users whenever a room has reached or near it's visitor limit, as well as to adapt people to the new normal arrangement. Among 6 beacons have been tested, Digoo Bytereal iBeacon BLE 4.0 and DS Beacon V1.0 are the most versatile and will be used in the next experiments. One of the limitations for this research is that depending on the limited number of BLE Beacon that used in the experiments, including all their features.

For the next research, big data infrastructure will be prepared using cloud technology, including the data warehouse technology as part of the back-end system using Relational Database Management System (RDBMS) or non-RDBMS. Furthermore, data analysis of the coordinates, distances and density of visitors are important to determine the behavior of visitors, so that the sequence points and patterns can be seen in real time. Which is then visualized as a reporting dashboard for the requirement from the event organizer to make decisions.

\section{ACKNOWLEDGEMENT}

This research is funded by Ministry of Education, Culture, Research and Tecnology, Indonesia with the scheme of Penelitian Terapan Unggulan Perguruan Tinggi (PTUPT), contract no. 002/SP2H/RTJAMAK/LL4/2021.

\section{REFERENCES}

Adiputra, W., Purnama, J., and Anthony, R. (2017). Intellivent: A Business Intelligence Platform for Event Management using Gamified Mobile Application and QR Code, Journal of Applied Information, Communication and Technology, 4(2).

Buathong, K. and Lai, P.C. (2017), Perceived attributes of event sustainability in the MICE industry in Thailand: A viewpoint from governmental, academic, venue and practitioner, Journal of Sustainability, 9 (7).

Cheng, R. S., Hong, W. J., Wang, J. S. and Lin, K. W. (2016). Seamless Guidance System Combining GPS, BLE Beacon, and NFC Technologies, Mobile Information Systems Journal, vol. 2016:1-12.

Christian, Eng, K. I. and Ipung, H. P. (2017). Hadoop Configuration Tuning for Performance Optimization, Journal of Applied Information, Communication and Technology, 4 (1) 
Galinium, M., Ferdinand, G., Dyondra, D.A., Zuhdi, R., Purnama, J., Kho, I.E.

Daniş, F. S. and Cemgil, A. T. (2017). Model-based localization and tracking using bluetooth low-energy beacons, Journal of Sensors, 17(11): 1-23.

Disimulacion, M. A. T. (2020). "MICE Tourism During Covid-19 and Future Directions for the New Normal," Asia Pacific International Events Management Journal, 2(1): 11-17.

Hamm, S., Frew, E. and Lade, C. (2018). Hybrid and virtual conferencing modes versus traditional face-to-face conference delivery: A conference industry perspective, Event Management Journal, 22 (5): 717-733.

Huh, J. and Seo, K. (2017). An Indoor Location-Based Control System Using, Journal of Sensors, 17(2917): 1-22.

lotbymukund, (2016), "How to Calculate Distance from RSSI value of the BLE Beacon", 2016, [Online]. Available: https://iotandelectronics.wordpress.com/2016/10/07/how-to-calculatedistance-from-the-rssi-value-of-the-ble-beacon/ (accessed in June2021)

Kim, S., Park, S., Sun, M. R., and Lee, J. H. (2016). A Study of Smart Beacon-based Meeting, Incentive Trip, Convention, Exhibition and Event (MICE) Services Using Big Data, Procedia Computer Science Journal, 91: 761-768

Li, G., Geng, E., Ye, Z., Xu, Y., Lin, J. and Pang, Y. (2018). Indoor Positioning Algorithm Based on the Improved, Journal of Sensors, 18 (2820): 1-15.

Ministry of Trade Republic of Indonesia (2011). Potensi Industri MICE Indonesia," Warta Ekspor, p. 19.

MIT License, (2020) "React Native (iOS and Android) library for Kontakt.io beacons (and all other beacons)", [Online]. Available: https://github.com/Driversnote-Dev/react-nativekontaktio (accessed in May 2021)

Syahlie, K., Eng, K. I., Lim, C., and Galinium, M. (2014). Hypervisors assessment in education industry: Using OpenBRR methodology, Proceedings of 2014 International Conference on Information, Communication Technology and System, 303-308.

Widjaja, A., Purnama, J., and Galinium, M. (2019). Implementation Of Mobile Application For A Museum By Using Internet Of Things Technology, in "Prosiding Konferensi Nasional Pengabdian Kepada Masyarakat dan Corporate Social Responsibility (PKM-CSR), 2: 166-176.

Wijaya, H., Erwin, A., Soetomo, A., and Galinium, M. (2013). Twitter Sentiment Analysis and Insight for Indonesian Mobile Operators, Information Systems International Conference (ISICO), 367.

Zhuang, Y., Yang, J., Li, Y., Qi, L., and El-Sheimy, N. (2016). Smartphone-Based Indoor Localization with Bluetooth Low Energy Beacons, Journal of Sensors, 16(1): 1-20. 